\title{
Analysis of the Depreciation of RMB in 2014
}

\author{
Huichao Gong \\ Department of Economics, Zhejiang University, Zhejiang Province, China \\ gonbc@sina.com
}

\begin{abstract}
In the first half of 2014, China's exchange rate has depreciated a lot. According to China's exchange rate data this article analyzes the reasons for the depreciation as well as the impact of it. Government forces and Chinese economic situation are both considered to be closely related to the weakening in exchange rate. In contrast little support is found for a long-term trend to depreciate because China's balance of payments continued to expand and post a twin surplus.
\end{abstract}

Index Terms - Exchange rate, RMB, Depreciation.

\section{Introduction}

There is a significant weakening in China's exchange rate. In Fig. 1, it can be seen that the yuan has slipped in value since mid-January.

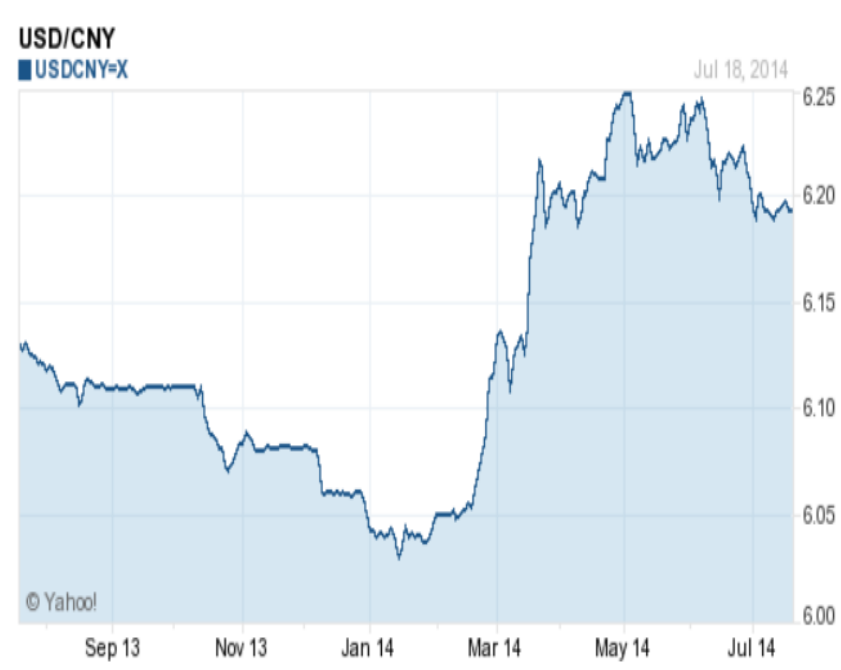

Fig. 1 RMB exchange rate against U.S. dollar

In my view, because of worries about financial stability China had temporarily issued a moderately relaxed monetary policy, but had not reversed its medium-term exchange rate strategy yet. Also China plans to introduce greater market forces into its economic system in the years ahead. But I do not think that China has decided to drive its exchange rate considerably lower for the long time.

My article proceeds as follows. The section two analyzes the reasons of the depreciation of RMB. The third and fourth sections outline in detail the positive and negative impact of the depreciation. In the fifth section the long-term trend of exchange rate is presented and the sixth section is the conclusion.

\section{Reasons for the Depreciation of RMB}

Apart from the government forces mentioned before, there are many other factors leading to the depreciation of RMB.

(1) Because of the warmer American economy and the unwinding of Quantitative Easing, many emerging economies have suffered capital outflow since the second half of last year. So there was a general depreciation of these countries' currencies in Fig. 2, Fig. 3 and Fig. 4. On March 20, 2014, the Fed declared that it would speed up the exit of QE and enter interest rate hike cycle in advance, which strengthened RMB's depreciation expectation.

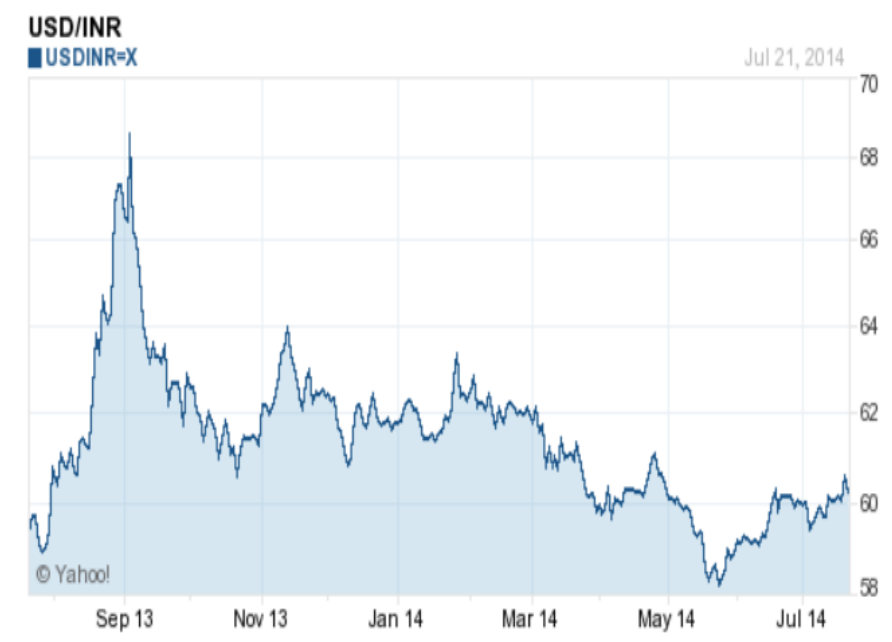

Fig. 2 Rupee exchange rate against U.S. dollar

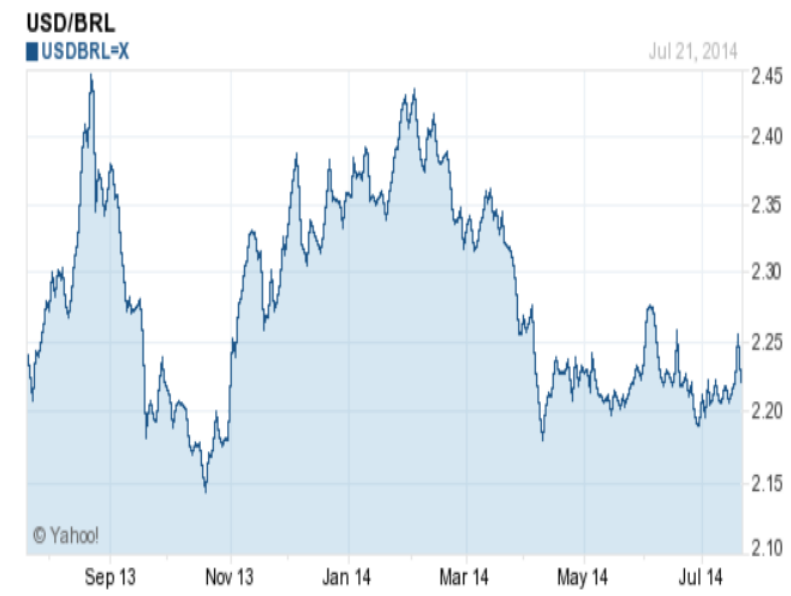

Fig. 3 BRL exchange rate against U.S. dolla 


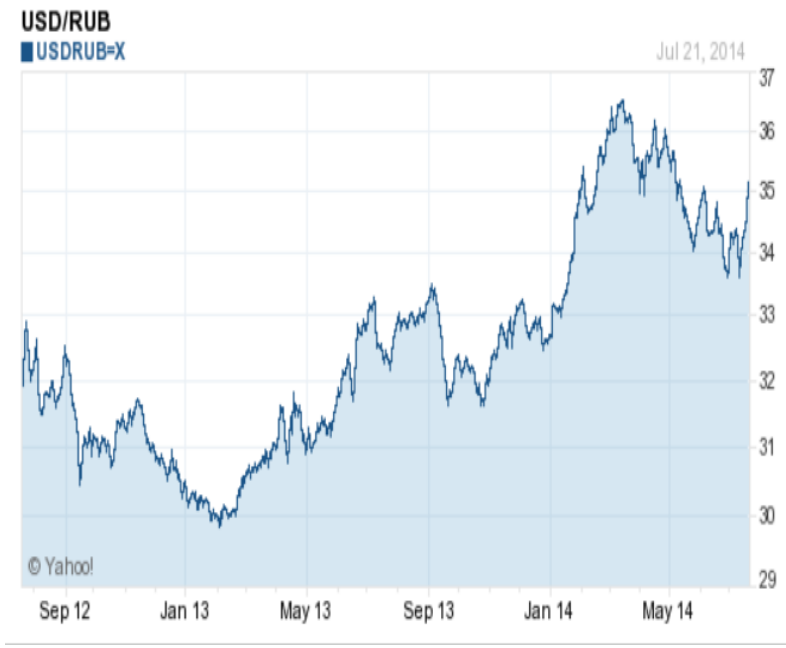

Fig. 4 Ruble exchange rate against U.S. dollar

(2) In 2014, China's economic growth slowed and the interest rate dropped in the same time. Thus, both the financial market and the real economy showed declines in capital demand, leading to a slowdown in capital inflow and the depreciation of the yuan.

(3) Although the government said it did not manipulate the currency, according to the changes in China's foreign exchange reserves and exchange rate, the government might have participated in it. If the currency depreciation is driven by economic fundamentals, China's funds outstanding for foreign exchange must decline as well. But in March, China's funds outstanding for foreign exchange increased greatly in Fig. 5, which implied government might have actively bought dollars and sold RMB.

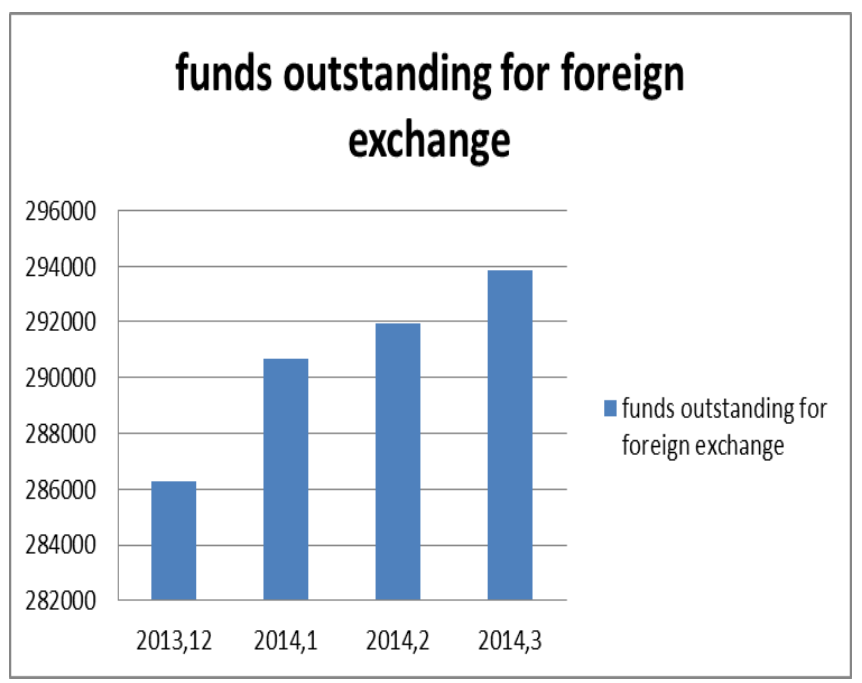

Fig. 5 China's funds outstanding for foreign exchange

\section{Positive Impact of the Depreciation of RMB}

(1) The government wants to divide the expectation of investors to reduce the perception of one-way trade.
At the beginning the depreciation, most people believed that RMB depreciation was purely conducted by government to mount a sharp but temporary squeeze carry trade [1]. So they still expected a long-term appreciation of RMB against the U.S. dollar. But the expectation reversed on March 7, 2014 , when RMB depreciated by $0.12 \%$ under the influence of China's first corporation bond default. But government seemed not to care about this and left the exchange rate to drop in the next few days.

Apparently, nowadays the depreciation of RMB managed to divide the expectation according to Nomura Securities' survey in Fig. 6. Nearly $67 \%$ people believe that RMB may continue to weaken, most of who are corporations and monetary market dealers. $33 \%$ people believe RMB will not continue to weaken, most of who are Asian banks and American hedge funds.

\section{$\mathrm{RMB}$ exchange rate expectation}

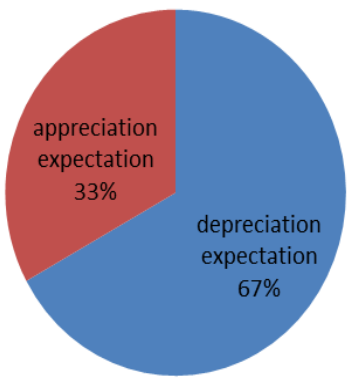

Fig. $6 \mathrm{RMB}$ exchange rate expectation

(2) According to the export data in Fig. 7, RMB has depreciated a lot, stimulating the export and also improved the current account.

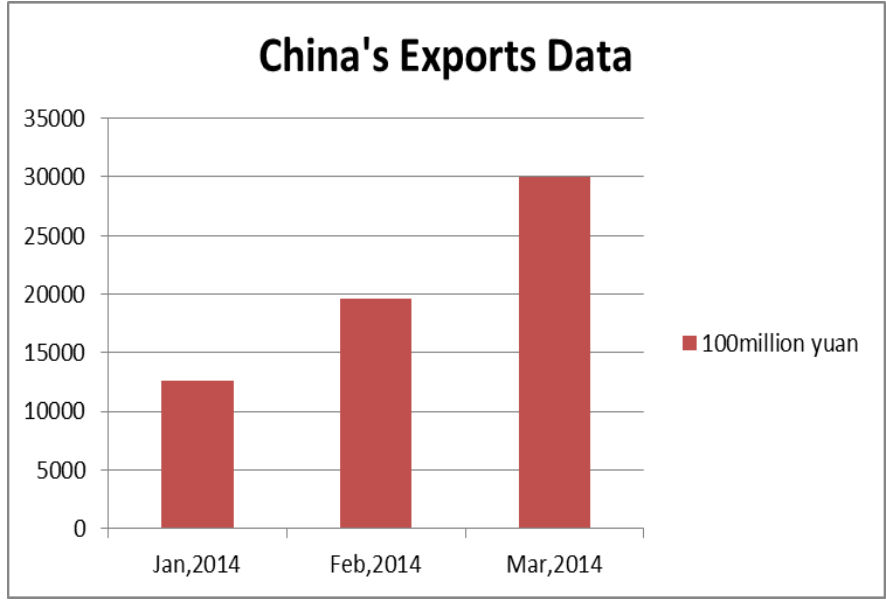

Fig. 7 China's Exports Data 


\section{Negative Impact of the Depreciation of RMB}

(1) The depreciation of RMB meant that the asset price dominated by RMB decreased, which may hurt China's property market and stock market. Nowadays, China's housing prices are still very high but there is strong expectation that housing prices may fall. If investors anticipate that RMB tends to continuingly depreciate, foreign capital will accelerate to withdraw from China's property market, which may result in a sharp drop of housing prices and disturb China's economy.

(2) The depreciation of BMB has bad influence on RMB internationalization. Up to now, China has not opened RMB capital market. Thus, keeping the faith that RMB will preserve or increase the value is very important. The market's general expectation that RMB will depreciate will hurt RMB internationalization.

According to the data from the Society for Worldwide Interbank Financial Telecommunication, or SWIFT, the value of transaction conducted in RMB fell by $8.5 \%$ in February from January, nudging the yuan down to the eighth most-used currency for payments from seventh position over the same period. The depreciation of RMB is one of factors leading to this [2].

\section{Long-term Analysis on RMB Exchange Rate}

It's not probable that RMB will form a long-term trend to depreciate because China's balance of payments continued to expand and post a twin surplus.

RMB exchange rate against U.S. dollar can be considered as the dollar's price dominated by RMB, which is decided by the demand and supply of RMB in exchange market. If there is a trade surplus, the supply of foreign currencies exceeds the demand and thus RMB tends to stay firm against foreign currencies, and vice versa.
In the next few years, China may still hold a twin surplus in international trade for the following reasons.

(1) With urbanization process, China's potential in labor market is still very big with great labor supply and low labor prices. Thus, Chinese companies still have the advantage of low labor cost.

(2) Because of the industrial upgrading process, there is great improvement in China's exports structure and the proportion of electromechanical products.

(3) With the economy recovery in European countries and the U.S., China's export volume may keep a high level. However, China is facing a slowdown in economy, which may lead to a slowdown in import volume. Also, the U.S. restricts many high-technique products' export to China.

So China may still hold a twin surplus in the next few years and keep RMB strong and it's not probable that RMB will form a long-term trend to depreciate.

\section{Summary}

From what has been mentioned above, there are many internal and external factors that drove RMB exchange rate low. However, I do not think that the government has decided to drive its exchange rate considerably lower in the long run to increase its share of global export market for many bad effects mentioned above. Also, I expect that exchange rate will not continuingly drop for a long time and it may pick up soon.

\section{References}

[1] Gavyn Davies, "Watch China's exchange rate policy," Financial Times. February 25, 2014. < Information on http://blogs.ft.com>

[2] Anjani Trivedi, "Use of Yuan as Global Payment Currency Falls," The Wall Street Journal. March 26, 2014. <Information on http://online.wsj.com> 